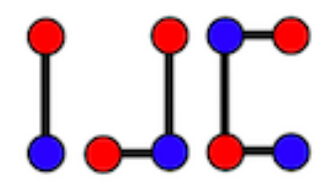

\title{
Locating-chromatic number of the edge-amalgamation of trees
}

\author{
H. Assiyatun, D.K. Syofyan, E.T. Baskoro \\ Combinatorial Mathematics Research Group, Faculty of Mathematics and Natural Sciences, \\ Institut Teknologi Bandung, Jalan Ganesa 10 Bandung 40132, Indonesia. \\ hilda@math.itb.ac.id,diankastikasyofyan@yahoo.com, ebaskoro@math.itb.ac.id
}

\begin{abstract}
The investigation on the locating-chromatic number for graphs was initially studied by Chartrand et al. on 2002. This concept is in fact a special case of the partition dimension for graphs. Even though this topic has received much attention, the current progress is still far from satisfaction. We can define the locating-chromatic number of a graph $G$ as the smallest integer $k$ such that there exists a proper $k$-coloring on the vertex-set of $G$ such that all vertices have distinct coordinates (color codes) with respect to this coloring. Not like the metric dimension of any tree which is completely solved, the locating-chromatic number for most types of trees are still open. In this paper, we study the locating-chromatic number of trees. In particular, we give lower and upper bounds of the locating-chromatic number of trees formed by an edge-amalgamation of the collection of smaller trees. We also show that the bounds are tight.
\end{abstract}

Keywords: locating-chromatic number, tree, edge-amalgamation

Mathematics Subject Classification : 05C12, 05C15

DOI: $10.19184 /$ ijc.2020.4.2.6

\section{Introduction}

The topic of locating-chromatic number of graphs was introduced by Chartrand et al. [5] on 2002. They determined the locating-chromatic numbers of some well-known classes of graphs,

Received: 11 April 2020, Revised: 17 May 2020, Accepted: 27 May 2020. 
i.e., paths, cycles, and double stars. They also characterized all graphs of order $n$ with locatingchromatic number $n$, i.e. multipartite complete graphs. This topic has received much attention. Inspired by Chartrand et al., other authors have determined the locating-chromatic numbers of some well-known classes of graphs. But the results are still limited. In particular for trees, the locating-chromatic number for most types of trees are still open. Some classes of trees with their locating-chromatic numbers known are amalgamations of stars and firecrackers by Asmiati et al. $[1,2]$, homogeneous lobsters and binary trees by Syofyan et al. [6, 7], and complete $n$-arry trees by Welyyanti et al. [9]. Furthermore, all trees on $n$ vertices with locating-chromatic number 3 or $n-t$ where $2 \leq t<\frac{n}{2}$ have been successfully characterized, see [4] and [8], respectively. In this paper, our aim is to determine the locating-chromatic number of the edge-amalgamation of trees. We then estimate the locating-chromatic numbers for some structures of trees obtained by the edge-amalgamation of trees.

Throughout this paper, we only deal with connected graphs. Let $G=(V, E)$ be a connected graph. For $u, v \in V(G)$, let $d(u, v)$ denote the distance between $u$ and $v$. A $k$-coloring of $G$ is a function $c: V(G) \rightarrow\{1,2, \ldots, k\}$ such that $c(u) \neq c(v)$ for any two adjacent vertices $u$ and $v$. In other words, $c$ is a partition $\Pi$ of $V(G)$ into color classes $C_{1}, C_{2}, \ldots, C_{k}$, where the vertices of $C_{i}$ are colored by $i$ for $1 \leq i \leq k$. The color code of vertex $u$ in $G$, denoted by $c_{\Pi}(u)$, is defined to be the ordered $k$-tuple $\left(d\left(u, C_{1}\right), d\left(u, C_{2}\right), \ldots, d\left(u, C_{k}\right)\right)$, where $d\left(u, C_{i}\right)=\min \left\{d(u, x) \mid x \in C_{i}\right\}$ for $1 \leq i \leq k$. If any two distinct vertices of $G$ have distinct color codes, then $c$ is called a locating $k$-coloring of $G$. Moreover, the least integer $k$ such that there is a locating-coloring in $G$ is called the locating-chromatic number of $G$, denoted by $\chi_{L}(G)$.

The following two results are natural consequences and showed in [5].

Lemma 1.1. Let $G$ be a connected non-trivial graph. Let $c$ be a locating coloring of $G$ and $u, v \in V(G)$. If $d(u, w)=d(v, w)$ for every $w \in V(G) \backslash\{u, v\}$, then $c(u) \neq c(v)$.

Corollary 1.1. If $G$ is a connected graph containing a vertex adjacent to $k$ leaves of $G$, then $\chi_{L}(G) \geq k+1$.

\section{Main Results}

For $i=1,2, \ldots, t$, let $T_{i}$ be a tree with a fixed edge $e_{o_{i}}$ called the terminal edge. The edgeamalgamation of all these trees $T_{i} s$, denoted by Edge-Amal $\left\{T_{i} ; e_{o_{i}}\right\}$, is a tree formed by taking all these trees $T_{i} \mathrm{~s}$ and identifying their terminal edges. In this section, we will derive the (lower and upper) bounds for the locating-chromatic number of the edge-amalgamation of trees.

Let $T$ be a tree. A stem is a vertex in $T$ that is adjacent to a leaf. A pendant edge is an edge in $T$ incident to a leaf in a tree. For any vertices $u$ and $v$ in $T$, we denote by ${ }_{u} P_{v}$ the unique path connecting $u$ and $v$. Let $u \in V(T)$ and define $N(u)=\{x \in V(T) \mid d(u, x)=1\}$. For a $k$-locating-coloring $c$ of $T$, we denote $c(N(u))=\{c(v) \mid v \in N(u)\}$.

For $i=1,2, \ldots, t$, let $T_{i}$ be a tree with a chosen terminal edge $e_{o_{i}}=s_{i} l_{i}$, where $s_{i}$ is a stem and $l_{i}$ is a leaf. For any stem $z$ of a tree $T_{i}$ we denote $N_{p}(z)$ is the set of pendant vertices adjacent to stem $z$. Let $m_{i}$ be the number of pendant edges adjacent to stem $s_{i}$ and $r_{i}=\max \left\{\left|N_{p}(z)\right| z\right.$ is a stem of $\left.T_{i}\right\}$. Next, in Edge-Amal $\left\{T_{i} ; e_{o_{i}}\right\}$, we denote $s=s_{i}$ and $l=l_{i}$. 
Theorem 2.1. Let Edge-Amal $\left\{T_{i} ; e_{o_{i}}\right\}$ be an edge-amalgamation of $t$ disjoint trees $T_{i}$. Then, $\max \left\{r_{i}+1,2+\sum_{i=1}^{t}\left(m_{i}-1\right)\right\} \leq \chi_{L}\left(\right.$ Edge-Amal $\left.\left\{T_{i} ; e_{o_{i}}\right\}\right) \leq 2+\sum_{i=1}^{t}\left(\chi_{L}\left(T_{i}\right)-2\right)$.

Proof. For $i=1,2, \ldots, t$, let $\chi_{L}\left(T_{i}\right)=k_{i}$. Let $c_{i}$ be a $k_{i}$-locating coloring of $T_{i}$ such that $c_{i}\left(s_{i}\right)=$ 1 and $c_{i}\left(l_{i}\right)=2$. Define $A=\left\{v \in V\left(T_{i}\right) \mid c_{i}(v)=1, \forall i \in[1, t]\right\}$ and $B=\left\{v \in V\left(T_{i}\right) \mid c_{i}(v)=\right.$ $2, \forall i \in[1, t]\}$. Now, define $c: V\left(\right.$ Edge-Amal $\left.\left\{T_{i} ; e_{o_{i}}\right\}\right) \rightarrow\left\{1,2, \ldots, 2+\Sigma_{i=1}^{t}\left(k_{i}-2\right)\right\}$ as follows

$$
c(x)= \begin{cases}1, & \text { if } x \in A \\ 2, & \text { if } x \in B \\ c_{1}(x), & \text { if } x \in V\left(T_{1}\right) \\ c_{i}(x)+\Sigma_{j=2}^{i}\left(k_{j-1}-2\right), & \text { if } x \in V\left(T_{i}\right) \backslash(A \cup B), \text { for all } i>1 .\end{cases}
$$

Since the coloring $c$ preserves the locating coloring in every tree $T_{1}, T_{2}, \ldots, T_{t}$, two vertices $u$ and $v$ where $c(u)=c(v)$ and $c(N(u))=c(N(v))$ only occur for two cases below.

1. $u, v \in V\left(T_{i}\right)$ for some $i$.

Then, their color codes are distinguished by the $k_{i}$-locating coloring $c_{i}$ of $T_{i}$. Therefore, these vertices are also distinguished by $c$.

2. $u \in V\left(T_{i}\right)$ and $v \in V\left(T_{j}\right)$ for some $i \neq j$.

Let $c(u)=c(v)=1$. Since $c_{i}$ is a $k_{i}$-locating coloring and by the definition of the coloring $c$, there exists integer $p \neq 1,2$ such that $c(x)=p$ for some $x \in N^{2}(s)$ and $x \in T_{i}$. Thus, we have:

$$
d_{T}\left(u, C_{p}\right) \leq d_{T}(u, s)
$$

and

$$
d_{T}(v, s)+1 \leq d_{T}\left(v, C_{p}\right) \leq d_{T}(v, s)+2 .
$$

Similarly, consider the subtree $T_{j}$. Since $c_{j}$ is a $k_{j}$-locating coloring and by the definition of the coloring $c$, there exists integer $q \neq 1,2$ and $q \neq p$ such that $c(y)=q$ for some $y \in N^{2}(s)$ and $y \in T_{j}$. Thus, we have:

$$
d_{T}\left(v, C_{q}\right) \leq d_{T}(v, s)
$$

and

$$
d_{T}(u, s)+1 \leq d_{T}\left(u, C_{q}\right) \leq d_{T}(u, s)+2 .
$$

Now, if $d_{T}\left(u, C_{p}\right)=d_{T}\left(v, C_{p}\right)$ then from Eqs (1), (2), (3) and (4), we have that:

$$
d_{T}\left(v, C_{q}\right)<d_{T}(v, s)+1 \leq d_{T}\left(v, C_{p}\right)=d_{T}\left(u, C_{p}\right) \leq d_{T}(u, s)<d_{T}\left(u, C_{q}\right) .
$$

Thus, we have that $d_{T}\left(u, C_{q}\right) \neq d_{T}\left(v, C_{q}\right)$. Therefore, the color codes of $u$ and $v$ are different. A similar argument holds for the case $c(u)=c(v)=2$.

Thus, all vertices of the Edge-Amal $\left\{T_{i} ; e_{o_{i}}\right\}$ have distinct color codes. We conclude that

$$
\chi_{L}\left(\text { Edge-Amal }\left\{T_{i} ; e_{o_{i}}\right\}\right) \leq 2+\sum_{i=1}^{t}\left(k_{i}-2\right) .
$$


Next, since there is a stem adjacent to $\max \left\{r_{i}, 1+\sum_{i=1}^{t}\left(m_{i}-1\right)\right\}$ leaves, by Corollary 1.1

$$
\chi_{L}\left(\text { Edge-Amal }\left\{T_{i} ; e_{o_{i}}\right\}\right) \geq \max \left\{r_{i}+1,2+\sum_{i=1}^{t}\left(m_{i}-1\right)\right\} \text {. }
$$

The following two theorems show the existence of trees formed by an edge-amalgamation operation with the locating-chromatic number equals to the lower or upper bounds of Theorem 2.1. Furthermore, in Theorem 2.4, we give the example of trees formed by an edge-amalgation operation with the locating-chromatic number lies in between upper and lower bounds of Theorem 2.1.

Theorem 2.2. If $\chi_{L}\left(T_{i}\right)=k_{i}$ and $m_{i}=k_{i}-1$ for any $i$, then $\chi_{L}\left(\operatorname{Edge}-\operatorname{Amal}\left(T_{i} ; e_{o_{i}}\right)\right)=$ $2+\sum_{i=1}^{t}\left(\chi_{L}\left(T_{i}\right)-2\right)$.

Proof. By using the locating-coloring $c$ in proof Theorem 2.1, we have $\chi_{L}\left(\operatorname{Edge-Amal}\left(T_{i} ; e_{o_{i}}\right)\right) \leq$ $2+\sum_{i=1}^{t}\left(k_{i}-2\right)$.

Next, since there are $1+\sum_{i=1}^{t}\left(k_{i}-2\right)$ leaves adjacent to a stem in $\operatorname{Edge-Amal}\left(T_{i} ; e_{o_{i}}\right)$, by Lemma $1.1 \chi_{L}\left(\operatorname{Edge}-\operatorname{Amal}\left(T_{i} ; e_{o_{i}}\right)\right) \geq 2+\sum_{i=1}^{t}\left(k_{i}-2\right)$. So, we conclude that

$$
\chi_{L}\left(\operatorname{Edge}-\operatorname{Amal}\left(T_{i} ; e_{o_{i}}\right)\right)=2+\sum_{i=1}^{t}\left(k_{i}-2\right) .
$$

Let $G_{w_{i}}$ be a tree having a pendant $e_{o_{i}}$ as depicted in Figure 1 , where $w_{i} \geq 2$.

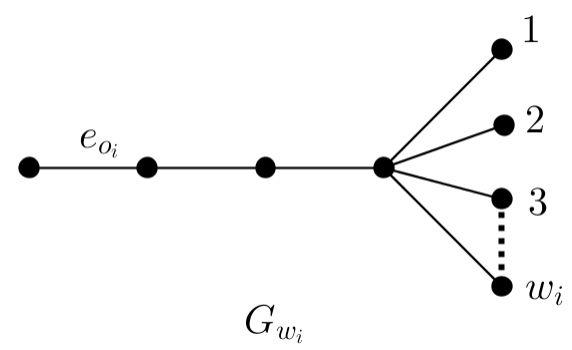

Figure 1. A tree $G_{w_{i}}$ where $w_{i} \geq 2$.

Theorem 2.3. For $i=1,2, \ldots, t$, let $T_{i}=G_{w_{i}}$. If $t \leq \max \left\{w_{i} \mid i \in[1, t]\right\}$, then

$$
\chi_{L}\left(\operatorname{Edge}-\operatorname{Amal}\left(T_{i} ; e_{o_{i}}\right)\right)=\max \left\{w_{i}+1 \mid i \in[1, t]\right\} .
$$


Proof. Let $r=\max \left\{w_{i} \mid i \in[1, t]\right\}$. Since there are $r$ leaves adjacent to a stem in Edge-Amal $\left(T_{i} ; e_{o_{i}}\right)$, by Lemma $1.1 \chi_{L}\left(\operatorname{Edge}-\operatorname{Amal}\left(T_{i} ; e_{o_{i}}\right)\right) \geq r+1$.

Now, let $T_{i}=G_{w_{i}}$ such that $w_{1} \leq w_{2} \leq \ldots \leq w_{t}$. We denote $x_{i}, y_{i}, z_{i j}$ the non stem vertex, the stem adjacent to $w_{i}$ leaves, and all leaves adjacent to $y_{i}$, respectively.

Define a coloring $c: V\left(\right.$ Edge-Amal $\left.\left\{T_{i} ; e_{o_{i}}\right\}\right) \rightarrow\{1,2, \ldots, r+1\}$ as follows

$$
c(u)= \begin{cases}1, & \text { if } u=s \\ 2, & \text { if } u=l \text { or } u=x_{i} \text { for } 1 \leq i \leq t-1 \text { and } i \neq 2 \\ 3, & \text { if } u=x_{2} \\ i, & \text { if } u=y_{i} \\ j, & \text { if } u=z_{i j} \text { and } i \neq j \\ r+1, & \text { if } u=z_{i j} \text { and } i=j .\end{cases}
$$

By this coloring, any two vertices $u$ and $v$ satisfying $c(u)=c(v)$ and $c(N(u))=c(N(v))$ only occur for the pair of vertices $s$ and $y_{i}$ for $w_{1}=2$, and the pair of vertices $l$ and $x_{1}$. Their color codes are distinguished by the last ordinate (their distances to a vertex in the color class $r+1$ ). Hence, all vertices have distinct color codes. So, $\chi_{L}\left(\operatorname{Edge}-\operatorname{Amal}\left(T_{i} ; e_{o_{i}}\right)\right) \leq \max \left\{r_{i}+1\right\}$.

Let $H_{m}$ be a tree having a pendant $e_{o_{i}}$ as depicted in Figure 2, where $m \geq 3$.

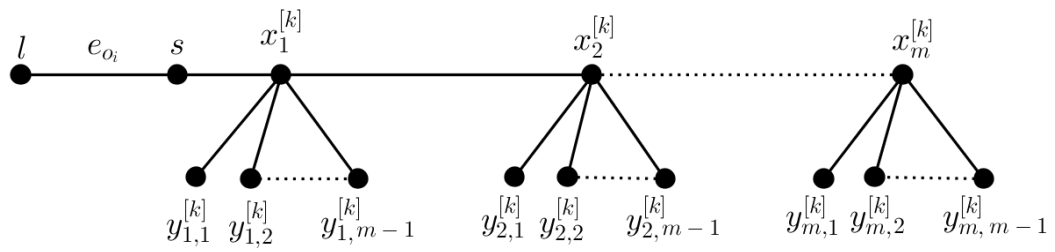

Figure 2. A tree $H_{m}$ where $m \geq 3$.

Theorem 2.4. For $i=1,2, \ldots, t$, let $T_{i}=H_{m}$. We have that $\chi_{L}\left(\operatorname{Edge-Amal}\left(T_{i} ; e_{o_{i}}\right)\right)=m+2$, if $2 \leq t \leq m$.

Proof. Let $t \in[2, m]$. Then, there are $t m$ stems and each is adjacent to $m$ leaves in graph Edge-Amal $\left(T_{i} ; e_{o_{i}}\right)$. We suppose that $\chi_{L}\left(\right.$ Edge-Amal $\left.\left(T_{i} ; e_{o_{i}}\right)\right)=m+1$. Then, there are $m+1$ possibilities to coloring all stems and their neighbors in $\operatorname{Edge-Amal}\left(T_{i} ; e_{o_{i}}\right)$. Since $t \geq 2$, there are at least two stems having the same color. Therefore, the color codes of these stems are the same, a contradiction to $\chi_{L}\left(\operatorname{Edge}-\operatorname{Amal}\left(T_{i} ; e_{o_{i}}\right)\right)=m+1$. So,

$$
\chi_{L}\left(\operatorname{Edge}-\operatorname{Amal}\left(T_{i} ; e_{o_{i}}\right)\right) \geq m+2 .
$$

Next, we define a coloring $c: V\left(\right.$ Edge-Amal $\left.\left\{T_{i} ; e_{o_{i}}\right\}\right) \rightarrow\{1,2, \ldots, m+2\}$ as follows: 


$$
c(u)= \begin{cases}1, & \text { if } u=s \\ 2, & \text { if } u=l \\ i+k, & \text { if } u=x_{i}^{[k]} \text { for } 1 \leq i \leq m-1, \text { and } 1 \leq k \leq t \\ k, & \text { if } u=x_{m}^{[k]} \text { for } 1 \leq k \leq t \\ j+k-1, & \text { if } u=y_{i, j}^{[k]} \text { and } j \neq(i+k) \bmod m, \text { for } 1 \leq i \leq m-1, \\ & 1 \leq j \leq m-1, \text { and } 1 \leq k \leq t \\ m+k-1, & \text { if } u=y_{i, j}^{[k]} \text { and } j=(i+k) \bmod m, \text { for } 1 \leq i \leq m-1, \\ & 1 \leq j \leq m-1, \text { and } 1 \leq k \leq t \\ j+k, & \text { if } u=y_{m, j}^{[k]} \text { for } 1 \leq k \leq t .\end{cases}
$$

Note that all the colors above in modulo $m+2$. We will show that $\chi_{L}\left(\operatorname{Edge}-\operatorname{Amal}\left(T_{i} ; e_{o_{i}}\right)\right) \leq$ $m+2$. Let $u$ and $v$ be any two vertices with $c(u)=c(v)$. Then, by the coloring $c, c(N(u)) \neq$ $c(N(v))$ because the $m-1$ neighbors colors of $u$ are permutation of $m-1$ neighbors colors of $v$ in modulo $m+2$. Hence, all vertices in $\operatorname{Edge-Amal}\left(T_{i} ; e_{o_{i}}\right)$ have distinct color codes. So, $\chi_{L}\left(\operatorname{Edge}-\operatorname{Amal}\left(T_{i} ; e_{o_{i}}\right)\right) \leq m+2$.

From Theorem 2.3, we shows the exact value of locating-chromatic number for some classes of trees. First, we give definition of some classes of trees and their locating-chromatic number, i.e. double stars, homogeneous caterpillars, and homogeneous lobsters. A double star, denoted by $S_{m, n}$ where $n \geq m \geq 1$, is the graph consisting of two stars $K_{1, n}$ and $K_{1, m}$ together with an edge joining their centers. Chartrand et al. [5] have proved $\chi_{L}\left(S_{m, n}\right)=n+1$. The homogeneous caterpillar $C(m, n)$ is the graph consisting of $m$ stars $K_{1, n}$ by linking the centers from each stars. Asmiati et al. [3] showed that the locating-chromatic number of homogeneous caterpillar is $n+1$ for $1 \leq m \leq n+1$, and $n+2$ for $m>n+1$. The homogeneous lobster $L b(m, n)$ is the graph obtained by attaching the centers of stars $K_{1, n}$ to each leaf of $C(m, n)$. Syofyan et al. [6] showed that the locating-chromatic number of the homogeneous lobster is $n+1$ if $m=1$, n+2 for $2 \leq m \leq 3(n=2)+1$, or $n+3$ for $m>3(n+2)+1$.

Based on Theorem 2.3 and the locating-chromatic numbers of double stars, homogeneous caterpillars, and homogeneous lobsters, we have the locating-chromatic number of edge-amalgamation of these trees as follows. The terminal edge in each tree is chosen from the edges incident to a stem having maximum leaves.

Corollary 2.1. For $i=1,2, \ldots, t$, let $T_{i}=S_{m, n}$. Then, $\chi_{L}\left(\operatorname{Edge}-\operatorname{Amal}\left(T_{i} ; e_{o_{i}}\right)\right)=t(n-1)+1$, if $n \geq m \geq 1$.

Corollary 2.2. For $i=1,2, \ldots, t$, let $T_{i}=C(m, n)$. If $1 \leq m \leq n+1$, then $\chi_{L}\left(\operatorname{Edge-Amal}\left(T_{i} ; e_{o_{i}}\right)\right)=t(n-1)+1$.

Corollary 2.3. For $i=1,2, \ldots, t$, let $T_{i}=L b(m, n)$. If $m=1$, then $\chi_{L}\left(\operatorname{Edge-Amal}\left(T_{i} ; e_{o_{i}}\right)\right)=$ $t(n-1)+1$.

\section{Acknowledgement}

This research has been supported by the Research Grant of "Riset Inovasi KK", Institut Teknologi Bandung and the Research Grant of "Penelitian Dasar Unggulan Perguruan Tinggi (PDUPT)", Ministry of Research and Technology / National Research and Innovation Agency, Indonesia. 


\section{References}

[1] Asmiati, H. Assiyatun, and E.T. Baskoro, Locating-chromatic number of amalgamation of stars, ITB J. Sci. 43 A (1) (2011), 1-8.

[2] Asmiati, E.T. Baskoro, H. Assiyatun, D. Suprijanto, R. Simanjuntak, and S. Uttunggadewa, The locating-chromatic number of firecracker graphs, Far East J. Math. Sci. 63:1 (2012), $11-23$.

[3] Asmiati, Bilangan kromatik lokasi graf pohon dan karakterisasi graf dengan bilangan kromatik lokasi 3, Disertasi Program Studi Doktor Matematika, Institut Teknologi Bandung, 2012 (in Indonesian).

[4] E.T. Baskoro and Asmiati, Characterizing all trees with locating-chromatic number 3, Electron. J. Graph Theory Appl. 1 (2) (2013), 109-117.

[5] G. Chartrand, D. Erwin, M.A. Henning, P.J. Slater, and P. Zhang, The locating-chromatic number of a graph, Bull. Inst. Combin. Appl. 36 (2002), 89-101.

[6] D.K. Syofyan, E.T. Baskoro, and H. Assiyatun, On the locating-chromatic number of homogeneous lobster, AKCE Int. J. Graphs Comb. 10 (3) (2013), 245-252.

[7] D.K. Syofyan, E.T. Baskoro, and H. Assiyatun, The locating-chromatic number of binary trees, Elsevier, The 2nd International Conference of Graph Theory and Information Security, 74 (2015), 79-83.

[8] D.K. Syofyan, E.T. Baskoro, and H. Assiyatun, Trees with certain locating-chromatic number, J. Math. Fund. Sci. 48 (1) (2016), 39-47.

[9] D. Welyyanti, E.T. Baskoro, R. Simanjuntak, and S. Uttunggadewa, On locating-chromatic number of complete n-ary tree, AKCE Int. J. Graphs Combin. 3 (2013), 309-315. 